\title{
Effects of Fermented Barley Extract on Antioxidant Status in Mice
}

\author{
Hideki HoKazono ${ }^{1,2^{*}}$, Toshiro OMORI ${ }^{1}$, Hiramitsu SuZuKI ${ }^{3}$ and Kazuhisa ONO ${ }^{2}$ \\ ${ }^{1}$ Frontier Research Center, Sanwa Shurui Co. Ltd., 2231-1 Yamamoto, Usa, Oita 879-0495, Japan \\ ${ }^{2}$ Department of Molecular Biotechnology, Graduate School of Advanced Sciences of Matter, Hiroshima University, 1-3-1 Kagamiyama, \\ Higashi-Hiroshima 739-8530, Japan \\ ${ }^{3}$ Laboratory of Food Science and Technology, Kagawa Nutrition University, 3-9-21, Chiyoda, Sakado, Saitama 350-0288, Japan
}

Received January 23, 2009; Accepted July 22, 2009

Effects of dietary supplementation with Fermented barley extract (FBE) on lipid metabolism and antioxidant status in mice were studied. In experiment 1 , male 5-month-old mice were fed either a control diet or an experimental diet containing $10 \%$ barley, fermented barley fiber (striated part of barley grain) or FBE for 3 months. In experiment 2, male 5-month-old mice were fed either a control diet or an experimental diet containing FBE or FBEP (adsorbed fraction of FBE on the hydrophobic resin) for 3 months. The thiobarbituric acid-reactive substances (TBARS) concentrations in both plasma and liver were significantly lower in the FBE and FBEP groups than the control group. Erythrocyte glutathione peroxidase activity was significantly higher in the FBEP group than in the other groups. Liver glutathione content was significantly higher in the FBEP group than in the control group. These results suggest that FBEP, prepared from the water-soluble fraction of barley-shochu distillery by-products, significantly reduces oxidative stress in the body.

Keywords: barley, shochu distillery by-product, thiobarbituric acid-reactive substances, glutathione, glutathione peroxidase

\section{Introduction}

Genuine shoch $u$ is a traditional Japanese spirit made from barley, rice, sweet potato, sugar cane or buckwheat. Japanese shochu production is characterized by the use of koji and by its method of distillation. Whereas malt is used in the fermentation of whiskey and beer, koji is used in shochu fermentation. Koji is peculiar to Asia and is produced by culturing fungi of the Aspergillus family (suited to temperate and humid climates) using cereal substrates such as rice or barley. Recent increases in shochu production have resulted in an enormous output of shochu distillery by-products (SDB). In the past, most of the SDB was dumped at sea, as industrial waste. However, the 1996 protocol of the London Convention stimulated research to develop treatment methods in lieu of dumping, and to investigate any useful characteristics of SDB as a non-utilized resource. Subsequently, many methods have been developed to effectively utilize SDB. For example, there have been reports on the use of SDB as dried feed or fertilizer (Shimoda et al., 1995), a growth promoter

*To whom correspondence should be addressed. E-mail: hokazono-h@kokuzo.co.jp for broilers (Mahfudz et al., 1996), a seasoning (Yokoyama et al., 2001) and in anticancer food (Sasaki et al., 2005). SDB contains an abundance of cereal- and microbial-derived nutrients, and its composition varies depending on the raw material, raw material formula and distillation method. Previously, we have reported on the effects of barley-SDB in promoting the growth of enteric bacteria (Furuta et al., 1998), preventing fatty liver induction by orotic acid (Mochizuki et al., 2001) and preventing liver injury caused by D-galactosamine (Mochizuki et al., 2005). As barley-SDB has been found to provide health benefits (as described above), we renamed barley-SDB "Fermented barley (FB)" to avoid the negative waste-product connotation. However, investigation into the influence of FB fraction intake on animal and human health is necessary. Two experiments using mice were conducted in an effort to elucidate the effects of oral administration of the extract fraction from FB on the body.

\section{Materials and Methods}

Materials Pearled barley (PB; barley pearled approximately $65 \%$ of its initial weight), purchased from Ishibashikohgyo Co., Ltd. (Fukuoka, Japan), was ground into flour 
and used in the experiment. FB, provided by Sanwa Shurui Co. Ltd. (Usa, Oita, Japan), was prepared using PB as the raw material. To produce steamed barley, PB was allowed to absorb water until a 40\% (w/w) water content was achieved, steamed for $40 \mathrm{~min}$, and subsequently cooled to $40^{\circ} \mathrm{C}$. The barley-koji was produced by inoculating the steamed barley with white koji mold (Aspergillus kawachii) (1 kg/ton of barley), which was maintained at $38^{\circ} \mathrm{C}$ and $95 \%$ relative humidity (RH) for $24 \mathrm{~h}$ with a subsequent incubation at $32^{\circ} \mathrm{C}$ and $92 \% \mathrm{RH}$ for $20 \mathrm{~h}$. The seed mash was prepared with 3.6 $\mathrm{kL}$ water, $30 \mathrm{~L}$ of shochu-yeast (Saccharomyces cerevisiae) preculture $\left(3 \times 10^{8} \mathrm{cfu} / \mathrm{mL}\right)$ and 3 tons of barley-koji. The seed mash was fermented for 5 days at $25^{\circ} \mathrm{C}$. The main mash was prepared by adding 7 tons of steamed barley and $11.4 \mathrm{~kL}$ of water to the seed mash. The main mash was fermented for 11 days at $25^{\circ} \mathrm{C}$. After fermentation, the main mash was subjected to single batch distillation to obtain $10 \mathrm{~kL}$ of unrefined barley-shochu and $15 \mathrm{~kL}$ of FB. FB was filtered with a stainless-steel mesh net $(1 \mathrm{~mm})$. The resulting residual substance, named fermented barley fiber (FBF), was dried with heated air and milled. The extracted liquid was then filtered using a ceramic filter (porosity, $0.2 \mu \mathrm{m}$ ) to remove solid residues, such as plant cell walls and microbial cells. Subsequently, the aqueous solution, named fermented barley extract (FBE), was freeze-dried and mixed with $50 \%$ (w/w) water-soluble dextrin (Pinedex $100^{\mathrm{TM}}$; Matsutani Chemical Industry Co., Ltd., Hyogo, Japan) as an excipient. A 10-L volume of FBE before concentration and drying was subjected to an Amberlite FPX66 ${ }^{\mathrm{TM}}$ (Rohm and Haas, USA) column $(80 \times 10 \mathrm{~cm}$ I.D.) equilibrated with distilled water. After washing with distilled water, the trapped material was eluted with $75 \%$ ethanol. The eluted fraction was freeze-dried. As a result, approximately $100 \mathrm{~g}$ of freeze-dried sample, named FBEP, was obtained from $10 \mathrm{~kg}$ of $\mathrm{PB}$. The recovery rates of $\mathrm{FB}$, FBE and FBEP from PB were $20 \%, 10 \%$ and $1 \%$ on a dry weight basis, respectively. The nutritional components of the samples were analyzed and are shown in Table 1.

Animals Male Crlj:CD-1 (ICR) mice (5 weeks old) were obtained from Charles River Japan Inc. (Atsugi, Kanagawa, Japan). All animals were switched from a laboratory diet, MF (Oriental Yeast Co., Ltd., Tokyo, Japan), to the experimental diets at 5 months of age. Forty-eight (Exp. 1) or thirty-two (Exp. 2) mice were randomly divided into six or four groups of eight animals each, and housed in suspended stainless-steel cages with wire mesh bottoms. The animal room was kept at $24 \pm 0.5^{\circ} \mathrm{C}$ with the $\mathrm{RH}$ at $65 \pm 5 \%$. Room lighting consisted of 12-h periods of light and dark. Mice were given free access to the diets and water. All mice were fed the experimental diets for 3 months. Food consumption (g/day) was observed and body weights were measured once a week. All mice were maintained according to the guidelines for experimental animals of the National Food Research Institute, Japan.

Diet Each diet contained 5\% lipid, 20\% protein and $48.8 \%$ carbohydrate sources, in addition to the following components: granulated sugar, $15 \%$; cellulose powder, $5 \%$; salt mixture, 4\%; vitamin mixture, $2 \%$; and L-methionine, $0.2 \%$. The salt and vitamin mixtures were purchased from Oriental Yeast Co., Ltd. (Tokyo, Japan). In these diets, lard and casein were used as lipid and protein sources, respectively. Furthermore, dextrin and corn starch were used as carbohydrate sources. In experiment 1 , the diets containing $0 \%$ or $10 \%$ of samples (PB, FBF or FBE) were used. In experiment 2 , the diets containing $0 \%$ of sample, $10 \%$ of $\mathrm{FBE}$ or $5 \%$ of FBEP were used. Amounts of lipid, protein and carbohydrate contained in experimental samples were deducted from the amount of lard, casein and cornstarch of the control diet in the preparation of experimental diets, respectively.

Preparation of plasma and erythrocyte lysate samples At the end of the feeding trials, all mice were fasted for 20 $\mathrm{h}$ before being anesthetized with diethyl ether. Blood was then collected from the inferior vena cava with a heparinized syringe and transferred to ice-cold tubes. Plasma and erythrocytes were separated by centrifugation at $900 \times g$ for 20 min at $4{ }^{\circ} \mathrm{C}$. In experiment 2 , erythrocytes were subsequently washed once with 10 volumes of cold $0.9 \% \mathrm{NaCl}$ solution

Table 1. Nutritional components of samples (g/100 g).

\begin{tabular}{lccrr}
\hline \multicolumn{1}{c}{ Components } & PB & FBF & FBE & FBEP \\
\hline Moisture & 15.8 & 6.0 & 5.1 & 6.2 \\
Crude protein & 6.0 & 19.6 & 18.9 & 39.2 \\
Crude fat & 1.3 & 13.3 & 0.0 & 0.3 \\
Ash & 0.7 & 1.9 & 2.6 & 3.7 \\
Total dietary fiber & 7.2 & 47.4 & 0.9 & 8.8 \\
$\quad$ Soluble fiber & $(4.9)$ & $(1.7)$ & $(0.9)$ & $(8.8)$ \\
$\quad$ Insoluble fiber & $(2.3)$ & $(45.7)$ & $(0.0)$ & $(0.0)$ \\
\hline
\end{tabular}

$\mathrm{PB}=$ Pearled barley flour; FBF $=$ Fermented barley fiber; FBE = Fermented barley extract; FBEP $=$ Fermented barley extract $P$. 
by centrifugation at $900 \times g$ for $20 \mathrm{~min}$ at $4^{\circ} \mathrm{C}$. The washed centrifuged erythrocytes were lysed by 4 volumes of cold deionized water, mixed and left at $4^{\circ} \mathrm{C}$ for $15 \mathrm{~min}$. Plasma and erythrocyte lysate samples were stored at $-30^{\circ} \mathrm{C}$ until required for analysis.

Preparation of liver homogenates After blood collection, the whole liver of each mouse was removed and homogenized with $1 / 15 \mathrm{~mol} / \mathrm{L}$ phosphate buffered saline $(\mathrm{pH}$ 7.4) using a Teflon-glass homogenizer. Tissue homogenates were stored at $-30^{\circ} \mathrm{C}$ until required for analysis.

Analytical procedures Total cholesterol, triacylglycerol and phospholipid concentrations in plasma samples and liver homogenates were determined by the enzymatic methods of Allain et al. (1974), Spayd et al. (1978) and Takayama et al. (1977), respectively. Plasma free fatty acid concentrations (in Exp. 1) were measured by the enzymatic method of Shimizu et al. (1979). The thiobarbituric acid-reactive substances (TBARS) concentrations in plasma were determined by the method of Yagi (1998), and those in tissues were determined by the method of Ohkawa et al. (1979), with a minor modification. The TBARS concentrations are presented as nmol malondialdehyde (MDA), using tetraethoxypropane as an external standard. In experiment 2, erythrocyte glutathione peroxidase (GPx) and superoxide dismutase (SOD) activities were determined using commercially available kits (BIOXYTECH GPX-340 ${ }^{\mathrm{TM}}$ and SOD-525 $5^{\mathrm{TM}}$, respectively). Liver glutathione (GSH) concentration was determined using a BIOXYTECH GSH- $420^{\mathrm{TM}}$ colorimetric assay kit. All of these kits were purchased from OXIS International, Inc. (Portland, USA).

Statistical Analyses All results were expressed as means \pm SD. The statistical significance of differences between dietary groups was determined by one-way analysis of variance using the STATISTICA statistical program package (StatSoft Inc., Okla., USA). When the F test was significant, comparisons between the dietary groups were performed using Duncan's multiple range test at $p<0.05$.
Experiment 1. The effects of FB on lipid metabolism in mice Food consumption was $4.5 \pm 0.1 \mathrm{~g} / \mathrm{day}$, and the differences between the dietary groups were not significant. The final body weights were as follows: control group, $50.0 \pm$ $4.5 \mathrm{~g}$; PB group, $48.8 \pm 5.0 \mathrm{~g}$; FBF group, $49.4 \pm 4.7 \mathrm{~g}$; FBE group, $48.3 \pm 4.8 \mathrm{~g}$. There were no significant differences in body weight between groups.

The effects of experimental diets on plasma lipid components and TBARS are shown in Table 2. There were no significant differences in total cholesterol concentration among the groups. Triacylglycerol concentration was significantly lower in the PB group than in the control group. Phospholipid concentration tended to be higher in the FBF group and lower in the PB group. Free fatty acid concentrations were significantly lower in PB flour and FB groups, and especially so in the FBE group, as compared to the control group. Only the FBE group was significantly lower in TBARS concentration than the control group.

The effects on liver lipids and TBARS are shown in Table 3. Total cholesterol concentration was significantly higher in the PB and FBF groups than in the control group. Phospholipid concentration tended to be higher in the FBF group. TBARS concentration was significantly lower in the FBE group than in the control, $\mathrm{PB}$, and FBF groups.

Experiment 2. The effects of FBE and FBEP on the antioxidative status in mice Food consumption was $4.4 \pm 0.2 \mathrm{~g} /$ day, and the differences between the dietary groups were not significant. The final body weights were as follows: control group, $52.0 \pm 3.1 \mathrm{~g}$; FBE group, $51.1 \pm 4.4 \mathrm{~g}$; FBEP group, $50.2 \pm 3.2 \mathrm{~g}$. There were no significant differences in body weight between groups.

The plasma lipid concentration for each dietary group is presented in Table 4. No significant differences were found in total cholesterol, triacylglycerol or phospholipid concentrations among the groups. TBARS concentration was significantly lower in the FBE and FBEP groups than in the control group.

The erythrocyte GPx and SOD activities are shown in

\section{Results}

Table 2. Effect of PB, FBF and FBE on plasma lipids in mice (Exp. 1).

\begin{tabular}{lcrrr}
\hline & \multicolumn{4}{c}{ Dietary group } \\
\cline { 2 - 5 } & Control & PB & FBF & \multicolumn{1}{c}{ FBE } \\
\hline Total cholesterol $(\mathrm{mg} / \mathrm{dL})$ & $158.7 \pm 25.8$ & $139.0 \pm 23.0$ & $162.5 \pm 20.9$ & $134.8 \pm 34.8$ \\
Triacylglycerol $(\mathrm{mg} / \mathrm{dL})$ & $107.1 \pm 34.3^{\mathrm{b}}$ & $63.1 \pm 8.5^{\mathrm{a}}$ & $107.3 \pm 19.2^{\mathrm{b}}$ & $98.6 \pm 47.0^{\mathrm{ab}}$ \\
Phospholipids $(\mathrm{mg} / \mathrm{dL})$ & $225.2 \pm 31.6^{\mathrm{ab}}$ & $184.9 \pm 24.8^{\mathrm{a}}$ & $238.7 \pm 28.3^{\mathrm{b}}$ & $203.7 \pm 37.1^{\mathrm{ab}}$ \\
Free fatty acid $(\mu \mathrm{Eq} / \mathrm{L})$ & $917.2 \pm 104.1^{\mathrm{c}}$ & $647.0 \pm 70.7^{\mathrm{ab}}$ & $636.0 \pm 61.9^{\mathrm{ab}}$ & $564.5 \pm 103.0^{\mathrm{a}}$ \\
TBARS $(\mathrm{nmol} / \mathrm{mL})$ & $37.0 \pm 9.4^{\mathrm{bc}}$ & $28.9 \pm 5.1^{\mathrm{abc}}$ & $37.5 \pm 6.2^{\mathrm{c}}$ & $26.4 \pm 4.8^{\mathrm{a}}$ \\
\hline
\end{tabular}

Values are expressed as means $\pm \mathrm{SD}(\mathrm{n}=8)$. Values for each dietary group with different small letters in the same lipid fractions are significantly different at $p<0.05$ by Duncan's multiple range test. $\mathrm{PB}=$ Pearled barley flour; FBF $=$ Fermented barley fiber; FBE $=$ Fermented barley extract. 
Table 3. Effect of PB, FBF and FBE on liver lipids in mice (Exp. 1).

\begin{tabular}{lccrr}
\hline & \multicolumn{3}{c}{ Dietary group } \\
\cline { 2 - 5 } & \multicolumn{1}{c}{ Control } & \multicolumn{1}{c}{ PB } & \multicolumn{1}{c}{ FBF } & \multicolumn{1}{c}{ FBE } \\
\hline Total cholesterol (mg/g tissue) & $4.6 \pm 0.6^{\mathrm{a}}$ & $6.8 \pm 1.6^{\mathrm{b}}$ & $6.8 \pm 0.6^{\mathrm{b}}$ & $5.8 \pm 1.2^{\mathrm{ab}}$ \\
Triacylglycerol (mg/g tissue) & $46.3 \pm 16.5^{\mathrm{ab}}$ & $38.1 \pm 11.7^{\mathrm{ab}}$ & $56.9 \pm 8.8^{\mathrm{b}}$ & $61.1 \pm 24.2^{\mathrm{b}}$ \\
Phospholipids (mg/g tissue) & $16.8 \pm 0.9^{\mathrm{a}}$ & $17.4 \pm 0.9^{\mathrm{ab}}$ & $19.3 \pm 1.3^{\mathrm{b}}$ & $17.7 \pm 2.5^{\mathrm{ab}}$ \\
TBARS (nmol/g tissue) & $70.8 \pm 4.3^{\mathrm{b}}$ & $70.2 \pm 4.1^{\mathrm{b}}$ & $68.3 \pm 3.9^{\mathrm{b}}$ & $62.9 \pm 3.0^{\mathrm{a}}$ \\
\hline
\end{tabular}

Values are expressed as means $\pm \mathrm{SD}(\mathrm{n}=8)$. Values for each dietary group with different small letters in the same lipid fractions are significantly different at $p<0.05$ by Duncan's multiple range test. $\mathrm{PB}=$ Pearled barley flour; FBF $=$ Fermented barley fiber; FBE $=$ Fermented barley extract.

Table 4. Effect of FBE and FBEP on plasma lipids in mice (Exp. 2).

\begin{tabular}{lrrr}
\hline & \multicolumn{3}{c}{ Dietary group } \\
\cline { 2 - 4 } & \multicolumn{1}{c}{ Control } & \multicolumn{1}{c}{ FBE } & \multicolumn{1}{c}{ FBEP } \\
\hline Total cholesterol $(\mathrm{mg} / \mathrm{dL})$ & $171.8 \pm 38.9$ & $174.8 \pm 23.7$ & $157.2 \pm 28.1$ \\
Triacylglycerol $(\mathrm{mg} / \mathrm{dL})$ & $107.9 \pm 23.9$ & $91.4 \pm 16.0$ & $94.5 \pm 17.6$ \\
Phospholipids $(\mathrm{mg} / \mathrm{dL})$ & $261.7 \pm 47.5$ & $249.8 \pm 30.4$ & $226.7 \pm 38.6$ \\
TBARS $(\mathrm{nmol} / \mathrm{mL})$ & $37.4 \pm 14.8^{\mathrm{b}}$ & $22.0 \pm 6.0^{\mathrm{a}}$ & $23.9 \pm 7.5^{\mathrm{a}}$ \\
\hline
\end{tabular}

Values are expressed as means $\pm \mathrm{SD}(\mathrm{n}=8)$. Values for each dietary group with different small letters in the same lipid fractions are significantly different at $p<0.05$ by Duncan's multiple range test. FBE $=$ Fermented barley extract; FBEP $=$ Fermented barley extract $P$.

Table 5. Erythrocyte GPx activity was significantly higher in the FBEP group than in all the other groups. Erythrocyte SOD activity did not differ significantly among the groups.

The liver TBARS and GSH concentrations are presented in Table 6. TBARS concentration was significantly lower in the FBE and FBEP groups than in the control group. Hepatic GSH was significantly higher in the FBEP group than in the control group.

\section{Discussion}

There have been several reports demonstrating the beneficial physiological effects of barley on lipid metabolism in animals and humans (Oda et al., 1994; Yang et al., 2003; Ikegami et al., 1996; Behall et al., 2004; Shimizu et al., 2008). With respect to the animal experiments, many studies concerned themselves with high cholesterol and high-fat food, but few reports evaluated the long-term effect of barley on lipid metabolism in animals given a diet of ordinary nutritional composition. When the present experimental data is analyzed from the perspective of $\mathrm{PB}$, which is the raw material of FBF and FBE, the results are as follows. Plasma triacylglycerol concentration was significantly lower in the PB group than in the control group, whereas the FBE group was not different. With respect to liver lipid levels, the total cholesterol value was significantly higher in the PB group than in the control group, but did not differ significantly between FBE and control groups. Thus, it was suggested that FBE had little effect on lipid metabolism in mice fed a low fat diet. We thought that the reason FBE had no significant effect on lipid metabolism was that soluble dietary fiber (particularly beta-glucan) from barley had been degraded by fungal enzymes during the fermentation process. In addition, the safety of 3 months continuous administration of FBE and FBEP was confirmed in mice, as no abnormal variations in the organ weight and necropsy findings were observed.

TBARS concentrations in the plasma and liver were significantly lower in the FBE group than in the control group. Antioxidants, such as polyphenols, are believed to be involved in this effect. Some polyphenols have been identified in barley, and are reported to be proanthocyanidin oligomers (Mulkay et al., 1981; McMurrough et al., 1983). These polyphenols have reportedly shown strong antioxidant activity, and firmly trap hydrophilic radicals in aqueous solution systems (Ariga et al., 1988, 1990). However, components other than polyphenols may have been involved, as the FBE and FBEP prepared in this study were unrefined. Furthermore, because barley, a raw material of shochu, was not found to decrease the amount of systemic TBARS, the FBE components accentuating antioxidant properties in the body may have been due to an increase in antioxidant activity or the absorption of nutritional components produced, by fungi or yeast, during fermentation (Miyamoto et al., 2000; Lin et al., 2006). That is, it may be inferred that the fungi form an antioxidant, enzymatically decompose polyphenol glycosides, and produce a highly absorbable aglycon or an antioxidant peptide. In vitro anti-oxidant activity of the absorbed fraction 
Table 5. Erythrocyte (RBC) GPx and SOD activities of mice fed experimental diets for 3 months (Exp. 2).

\begin{tabular}{lccc}
\hline & \multicolumn{3}{c}{ Dietary group } \\
\cline { 2 - 4 } & Control & FBE & \multicolumn{1}{c}{ FBEP } \\
\hline GPx (U/mL RBC) & $40.5 \pm 6.8^{\mathrm{a}}$ & $40.3 \pm 3.6^{\mathrm{a}}$ & $60.4 \pm 4.8^{\mathrm{b}}$ \\
SOD (U/mL RBC) & $560.6 \pm 31.8$ & $543.8 \pm 31.2$ & $538.6 \pm 27.6$ \\
\hline
\end{tabular}

Values are expressed as means \pm SD $(n=8)$. Values for each dietary group with different small letters in the same column are significantly different at $p<0.05$ by Duncan's multiple range test. $\mathrm{FBE}=$ Fermented barley extract; FBEP $=$ Fermented barley extract $\mathrm{P}$.

Table 6. Liver TBARS and GSH concentrations of mice fed experimental diets for 3 months (Exp. 2).

\begin{tabular}{lrrr}
\hline & \multicolumn{3}{c}{ Dietary group } \\
\cline { 2 - 4 } & \multicolumn{1}{c}{ Control } & \multicolumn{1}{c}{ FBE } & \multicolumn{1}{c}{ FBEP } \\
\hline TBARS (nmol/g tissue) & $43.1 \pm 2.7^{\mathrm{b}}$ & $37.4 \pm 2.1^{\mathrm{a}}$ & $35.9 \pm 3.6^{\mathrm{a}}$ \\
GSH (mmol/g tissue) & $4.8 \pm 0.3^{\mathrm{a}}$ & $5.3 \pm 0.4^{\mathrm{ab}}$ & $5.9 \pm 0.4^{\mathrm{b}}$ \\
\hline
\end{tabular}

Values are expressed as means \pm SD $(n=8)$. Values for each dietary group with different small letters in the same column are significantly different at $p<0.05$ by Duncan's multiple range test. $\mathrm{FBE}=$ Fermented barley extract; FBEP $=$ Fermented barley extract $\mathrm{P}$.

of ethanol extract of $\mathrm{PB}$ on the hydrophobic resin was the same as for FBEP (data not shown). Further study on identifying the substances in FBEP that enhance antioxidant activity in vivo is required.

Results of numerous experiments have shown that dietary components rich in polyphenols and exhibiting high antioxidant capacity can influence biomarkers of antioxidants in rats, for example increased GPx and SOD activities (Ji et al., 2003; Leontowicz et al., 2003; Chen et al., 2004). Cellular antioxidant enzymes such as GPx and SOD have a central role in the control of reactive oxygen species. In mammalian cells, GSH and GPx constitute the principal antioxidant defense system (Raes et al., 1987; Ursini et al., 1995). In the present experiment, investigation of the in vivo effects on antioxidant index showed that erythrocyte GPx activity was significantly higher in the FBEP group than in the other groups. Moreover, hepatic GSH was significantly higher in the FBEP group than in the control group. GPx is an antioxidant enzyme that renders hydrogen peroxide or peroxidized lipid nontoxic by a two-electron reduction in the presence of GSH. GPx works together with SOD and catalase to play a role in the body's defense system against oxidative stress. GSH is known to be a very important component involved in toxin metabolism and antioxidant systems involved in protecting liver function (Hentze et al., 2000; Bajt et al., 2002; Li et al., 2003). The increase in the amount of liver GSH of animals fed FBEP is judged to be a piece of the evidence that supports the protective effect of FB on liver functions (Mochizuki et al., 2001, 2005). It was thought that consumption of GSH was suppressed as a result of increasing the activity of GPx by FBEP. Moreover, it is necessary to investigate the influence of FBEP on glutathione S-transferase (not evaluated in this study) and to clarify a detailed mechanism of the in vivo antioxidative activity of FBEP.

These findings show that FBEP has the effect of significantly reducing oxidative stress in the body. We consider it necessary to identify the components involved in these functions and, in the future, confirm their effects on humans.

\section{References}

Allain, C.C., Poon, L.S., Chan, C.S., Richmond, W. and Fu, P.C. (1974). Enzymatic determination of total serum cholesterol. Clin. Chem., 20, 470-475.

Ariga, T., Koshiyama, I. and Fukushima, D. (1988). Antioxidative properties of procyanidins B-1 and B-3 from azuki beans in aqueous systems. Agric. Biol. Chem., 52, 2717-2722.

Ariga, T. and Hamano, M. (1990). Radical scavenging action and its mode in procyanidins B-1 and B-3 from azuki beans to peroxyl radicals. Agric. Biol. Chem., 54, 2499-2504.

Bajt, M.L., Ho, Y.S., Vonderfecht, S.L. and Jaeschke, H. (2002). Reactive oxygen as modulator of TNF and fas receptor-mediated apoptosis in vivo: studies with glutathione peroxidase-deficient mice. Antioxid. Redox Signal., 4, 733-740.

Behall, K.M., Scholfield, D.J. and Hallfrisch, J. (2004). Diets containing barley significantly reduce lipids in mildly hypercholesterolemic men and women. Am. J. Clin. Nutr., 80, 1185-1193.

Chen, C.Y., Milbury, P.E., Kwak, H.K., Collins, F.W., Samuel, P. and Blumberg, J.B. (2004). Avenanthramides and phenolic acids from oats are bioavailable and act synergistically with vitamin $\mathrm{C}$ to enhance hamster and human LDL resistance to oxidation. $J$. 
Nutr., 134, 1459-1466.

Furuta, Y., Takashita, H., Omori, T., Sonomoto, K., Ishizaki, A., Shimoda, M. and Wada, H. (1998). Growth-stimulating effect of shochu wastewater on lactic acid bacteria and bifidobacteria. Ann. N. Y. Acad. Sci., 864, 276-279.

Hentze, H., Gantner, F., Kolb, S.A. and Wendel, A. (2000). Depletion of hepatic glutathione prevents death receptor-dependent apoptotic and necrotic liver injury in mice. Am. J. Pathol., 156, 2045-2056.

Ikegami, S., Tomita, M., Honda, S., Yamaguchi, M., Mizukawa, R., Suzuki, Y., Ishii, K., Ohsawa, S., Kiyooka, N., Higuchi, M. and Kobayashi, S. (1996). Effect of boiled barley-rice-feeding in hypercholesterolemic and normolipemic subjects. Plant Foods Hum. Nutr., 49, 317-328.

Ji, L.L., Lay, D., Chung, E., Fu, Y. and Peterson, D,M. (2003). Effects of avenanthramides on oxidant generation and antioxidant enzyme activity in exercised rats. Nutr. Res., 23, 1579-1590.

Leontowicz, M., Gorinstein, S., Leontowicz, H., Krzeminski, R., Lojek, A., Katrich, E., Cíz, M., Martin-Belloso, O., Soliva-Fortuny, R., Haruenkit, R. and Trakhtenberg, S. (2003). Apple and pear peel and pulp and their influence on plasma lipids and antioxidant potentials in rats fed cholesterol-containing diets. J. Agric. Food Chem., 51, 5780-5785.

Li, C., Liu, J., Waalkes, M.P. and Jaeschke, H. (2003). Gene array analysis of the hepatic response to endotoxin in glutathione peroxidase-deficient mice. Toxicol. Lett., 144, 397-406.

Lin, C.H., Wei, Y.T. and Chou, C.C. (2006). Enhanced antioxidative activity of soybean koji prepared with various filamentous fungi. Food Microbiol., 23, 628-633.

Mahfudz, L.D., Hayashi, K., Ikeda, M., Hamada, K., Ohtsuka, A. and Tomita, Y. (1996). The effective use of shochu distillery byproduct as a source of broiler feed. Jpn. Poult. Sci., 33, 1-7.

McMurrough, I., Loughrey, M.J. and Hennigan, G.P. (1983). Content of $(+)$-catechin and proanthocyanidins in barley and malt grain. J. Sci. Food Agric., 34, 62-72.

Miyamoto, Y., Noda, H., Ohya, H. and Kamada, H. (2000). SODlike activities of rice bran extracts after fermentation. Nippon Shokuhin Kagaku Kogaku Kaishi., 47, 214-219 (in Japanese).

Mochizuki, S., Miyamoto, A., Hagiwara, M., Takeshima, N. and Omori, T. (2001). Effects of barley shochu lees on the prevention of fatty livers in rats fed on orotic acid-containing diet. Nippon Jozokyokai Shi., 96, 559-563 (in Japanese).

Mochizuki, S., Miyamoto, A., Oga, S., Kai, C., Oshima, K., Tanaka, T., Hokazono, H., Takeshima, N. and Omori, T. (2005). Effects of barley shochu lees on D-galactosamine-induced hepatic injury in rats. Nippon Jozokyokai Shi., 100, 135-140 (in Japanese).

Mulkay, P., Touillaux, R. and Jerumanis, J. (1981). Proanthocyanidins of barley: separation and identification. J. Chromatogr., 208, 419-423.
Oda, T., Aoe, S., Imanishi, S., Kanazawa, Y., Sanada, H. and Ayano, Y. (1994). Effects of dietary oat, barley, and guar gums on serum and liver lipid concentrations in diet-induced hypertriglyceridemic rats. J. Nutr. Sci. Vitaminol. (Tokyo), 40, 213-217.

Ohkawa, H., Ohishi, N. and Yagi, K. (1979). Assay for lipid peroxides in animal tissues by thiobarbituric acid reaction. Anal. Biochem., 95, 351-358.

Raes, M., Michiels, C. and Remacle, J. (1987). Comparative study of the enzymatic defense systems against oxygen-derived free radicals: the key role of glutathione peroxidase. Free Radic. Biol. Med., 3, 3-7.

Sasaki, T., Abe, M., Nakayama, S., Moriyama, K., Tahara, H and Takita, T. (2005). Novel application of shochu distillery by-products to prophylaxis against mammary carcinogenesis induced by 7,12-dimethylbenz[a]anthracene in rats. Biosci. Biotechnol. Biochem., 69, 1898-1904.

Shimizu, C., Kihara, M., Aoe, S., Araki, S., Ito, K., Hayashi, K., Watari, J., Sakata, Y. and Ikegami, S. (2008). Effect of high $\beta$-glucan barley on serum cholesterol concentrations and visceral fat area in Japanese men - A randomized, double-blinded, placebo-controlled trial. Plant Foods Hum. Nutr., 63, 21-25.

Shimizu, S., Inoue, K., Tani, Y. and Yamada, H. (1979). Enzymatic microdetermination of serum free fatty acids. Anal. Biochem., $\mathbf{9 8}$, 341-345.

Shimoda, M., Nagano, S. and Wada, H. (1995). Development of dryer treatment system of distillery wastewater from barley-shochu making. Nippon Jozokyokai Shi., 90, 897-901 (in Japanese).

Spayd, R.W., Bruschi, B., Burdick, B.A., Dappen, G.M., Eikenberry, J.N., Esders, T.W., Figueras, J., Goodhue, C.T., LaRossa, D.D., Nelson, R.W., Rand, R.N. and Wu, T.W. (1978). Multilayer film elements for clinical analysis: applications to representative chemical determinations. Clin. Chem., 24, 1343-1350.

Takayama, M., Itoh, S., Nagasaki, T. and Tanimizu, I. (1977). A new enzymatic method for determination of serum choline-containing phospholipids. Clin. Chim. Acta., 79, 93-98.

Ursini, F., Maiorino, M., Brigelius-Flohé, R., Aumann, K.D., Roveri, A., Schomburg, D. and Flohé, L. (1995). Diversity of glutathione peroxidases. Methods Enzymol., 252, 38-53.

Yagi, K. (1998). Simple assay for the level of total lipid peroxides in serum or plasma. Methods Mol. Biol., 108, 101-106.

Yang, J.L., Kim, Y.H., Lee, H.S., Lee, M.S. and Moon, Y.K. (2003). Barley $\beta$-glucan lowers serum cholesterol based on the upregulation of cholesterol 7alpha-hydroxylase activity and mRNA abundance in cholesterol-fed rats. J. Nutr. Sci. Vitaminol. (Tokyo), 49, 381-387.

Yokoyama, S. and Tarumi, S. (2001). Production and some properties of low-salt seasoning from shochu distillery waste. Seibutsukogaku Kaishi., 79, 211-217 (in Japanese). 